\title{
sciendo

\section{Parameters that Affect Electricity Consumption in Fish Freezing. Case Study}

\author{
Edvins TEREHOVICS ${ }^{1 *}$, Ivars VEIDENBERGS ${ }^{2}$, Dagnija BLUMBERGA ${ }^{3}$ \\ ${ }^{1-3}$ Institute of Energy Systems and Environment, Riga Technical University, \\ Azenes iela 12/1, Riga, LV-1048, Latvia
}

\begin{abstract}
Reducing energy consumption in industry has become an important aspect on a global scale. Energy efficiency is one way of reducing energy consumption and promoting competitiveness. Increasing energy costs, security of energy supply, emissions from energy production have shown that current freezer design solutions are not sustainable. The food industry has a common tendency, whereby energy costs are only of secondary importance, unlike other production costs, resulting in minimal monitoring of energy consumption. Electricity consumption for freezer operation amounts to $20 \%$ of total electricity consumption. Within the framework of this study, electricity consumption for fish freezing and storing frozen fish and finished products, as well as the coefficient of performance (COP) for compressors and parameters affecting COP were analyzed. From the results it can be concluded that the specific consumption of electricity in freezing of fish is lower than that of frozen fish storage. The two-stage compressor COP ranges from 2.4 to 3.7, but the singlestage compressor COP ranges from 3.7 to 5.5. The pressure in the condenser and ammonia vapor temperature after the compressor is affected by the temperature of the water used to cool the condenser and compressors. As the temperature of the water used for cooling increases, the condenser and ammonia vapor temperature after the compressor increase, which in turn reduces the compressor COP.
\end{abstract}

Keywords - Coefficient of performance; compressor; condenser; energy; food industry

\section{INTRODUCTION}

Industrial freezing has been used for freezing fish since the early $20^{\text {th }}$ century. Freezing of fresh fish is used to store fish until the start of processing. The fish must be frozen quickly to keep the quality of the product after defrosting. Freezers for freezing fish are different from freezers with frozen fish in terms of dimensions and insulation thickness [1]-[3].

Reducing energy consumption in industry has become an important aspect on a global scale. Energy efficiency is one way of reducing energy consumption and promoting competitiveness. Increasing energy costs, security of energy supply, emissions from energy production have shown that current freezer design solutions are not sustainable. Solutions to reduce energy consumption should be explored to address these problems [4]-[6].

Electricity consumption for freezer operation amounts to $20 \%$ of total electricity consumption. Reducing electricity consumption can be achieved using the best available technology, but often these technologies are much more expensive than less efficient freezers. However, there are also low investment solutions, such as improving the system efficiency

\footnotetext{
* Corresponding author.

E-mail address: e.terehovics@inbox.lv 
using automated control systems [7]-[9]. The food industry has a common tendency, whereby energy costs are only of secondary importance, unlike other production costs, resulting in minimal monitoring of energy consumption [10].

There are many opportunities for reducing energy consumption in the fishery sector. Industrial freezers are one of the main electricity consumers in these companies. Potential energy efficiency improvement measures include better determination of refrigeration system capacity (current design refrigerating load is higher than actual freezing load), better system element performance adjustment and smoother system performance [11], [12].

Within the framework of this study, the operation of freezers in one fish processing company in Latvia is discussed. The company owns six freezers. Two freezers are used for freezing fish; four for storing frozen fish and finished products. All freezers are operated by 5 two-stage compressors and 3 single-stage compressors. Usually one two-stage and/ or one one-stage compressor is operating. One-stage compressors are used to provide the required temperatures in freezers where frozen fish and finished products are stored. Two-stage compressors, however, are used to maintain temperatures in the freezer where fresh fish are frozen. Ammonia is used as a refrigerant in the compressors, but local river water is used for cooling condensers and compressors.

The compressor performance is recorded in the journal. The following data is recorded every 2 hours:

- Ammonia temperature before and after two-stage compressor stages and flash chamber pressure;

- Ammonia temperature before and after one-step compressor;

- Water temperature before and after compressor and condenser as well as ammonia condensation pressure;

- Freezer temperature;

- Outdoor temperature;

- Temperature of the ammonia vapour fed to the freezer evaporators.

The study of the company's situation was conducted for the period from 09.2017 to 05.2018 .

Within the framework of this study, electricity consumption for freezing fish and storing frozen products, as well as coefficient of performance (COP) of compressors and parameters affecting COP were analysed.

\section{Methodology}

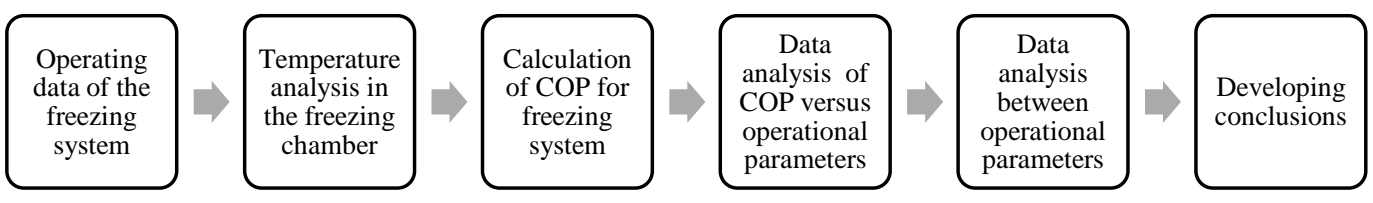

Fig. 1. Algorithm of the freezer electricity consumption analysis.

The algorithm consists of 6 blocks (Fig. 1). In the first block, data of the technical and operational parameters of the freezing system are collected. In the second block, based on the previously collected data, analysis of the freezer temperature is made. In the third block, calculation of coefficient of performance (COP) for the compressor unit is made. In the fourth block, data analysis of the compressor COP versus operational parameters such as pressure 
in the condenser and ammonia vapour temperature after the compressor are performed. In fifth block, data analyses between operational parameters are performed. The development of conclusions of the results took place in the last block.

The COP of a one-stage compressor is calculated by applying the following equation [13], [14]:

$$
\mathrm{COP}=\frac{\left(h_{1}-h_{5}\right)}{\left(h_{2}-h_{1}\right)},
$$

where

$h_{1} \quad$ Enthalpy of ammonia vapour before compressor, $\mathrm{kJ} / \mathrm{kg}$;

$h_{2} \quad$ Enthalpy of ammonia vapour after compressor, $\mathrm{kJ} / \mathrm{kg}$;

$h_{5} \quad$ Enthalpy of ammonia before evaporator, $\mathrm{kJ} / \mathrm{kg}$.

The numbers in the formula at the enthalpies denote the process points of the single-stage compressor thermodynamic cycle (Fig. 2).

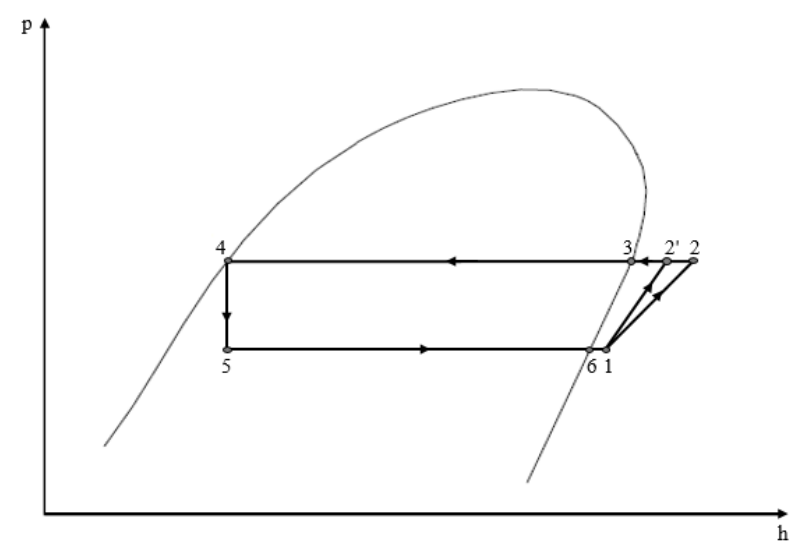

Fig. 2. Single-stage compressor operation in $P$ - $h$ diagram.

In the $P$ - $h$ diagram (Fig. 2), the thermodynamic process 1-2 describes the compressor's work during compression of ammonia vapour. Process 1-2 describes the theoretical work of the compressor during compression of ammonia vapour. Process 2-3 describes changes in ammonia vapour thermodynamic parameters during condensation. Process 4-5 describes the throttling of condensed ammonia vapour prior to discharge into the evaporator. Process 5-1 describes changes in ammonia thermodynamic parameters during evaporation (freezer cooling).

The COP of a two-stage compressor is calculated by applying the following equation [13], [14]:

$$
\mathrm{COP}=\frac{\left(h_{1}-h_{10}\right)}{\left[\left(h_{2}-h_{1}\right)+\frac{\left(h_{2}-h_{9}\right)\left(h_{5}-h_{3}\right)}{\left(h_{3}-h_{8}\right)}\right]},
$$


where

$h_{1} \quad$ Enthalpy of ammonia vapour before first stage compressor, $\mathrm{kJ} / \mathrm{kg}$;

$h_{2} \quad$ Enthalpy of ammonia vapour after first stage compressor, $\mathrm{kJ} / \mathrm{kg}$;

$h_{3} \quad$ Enthalpy of ammonia vapour before second stage compressor, $\mathrm{kJ} / \mathrm{kg}$;

$h_{5} \quad$ Enthalpy of ammonia vapour after second stage compressor, $\mathrm{kJ} / \mathrm{kg}$;

$h_{8} \quad$ Enthalpy of ammonia vapour after condenser before inlet in flash chamber, $\mathrm{kJ} / \mathrm{kg}$;

$h_{9} \quad$ Enthalpy of ammonia liquid in flash chamber, $\mathrm{kJ} / \mathrm{kg}$;

$h_{10} \quad$ Enthalpy of ammonia liquid before evaporator, $\mathrm{kJ} / \mathrm{kg}$.

The numbers in the formula at the enthalpies denote the process points of the two-stage compressor thermodynamic cycle (Fig. 3).

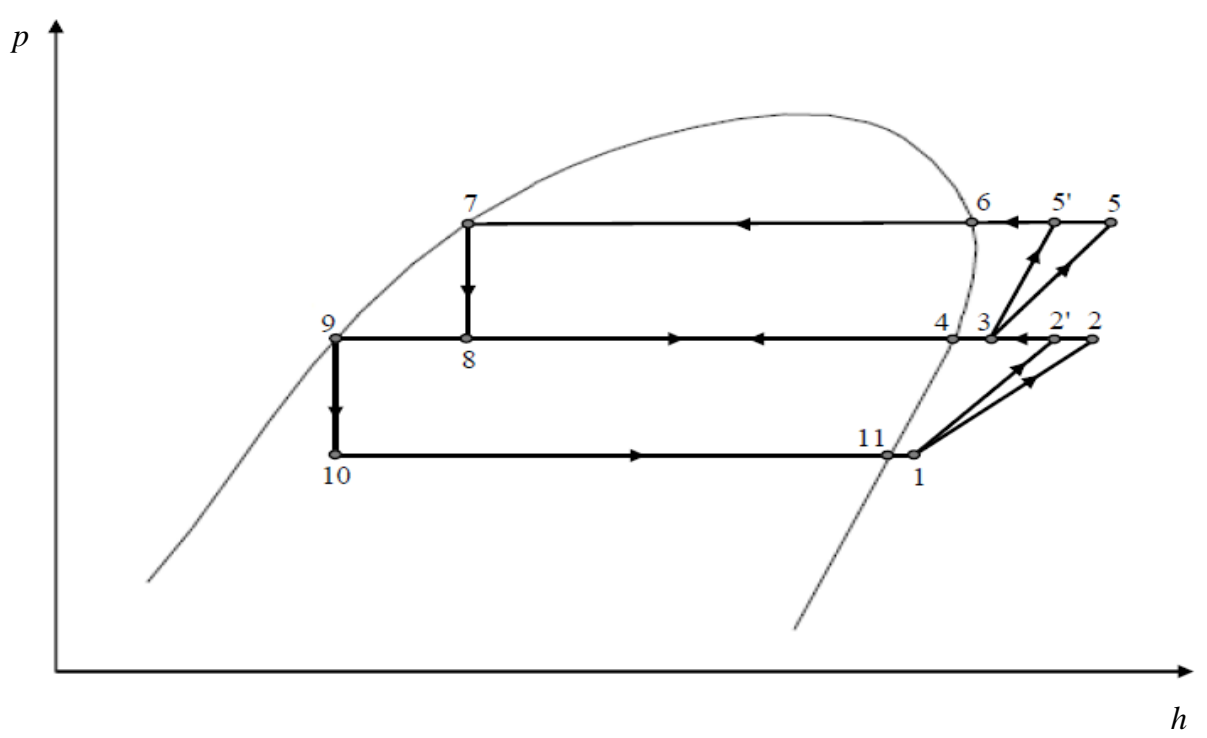

Fig. 3. Two-stage compressor operation in $P$ - $h$ diagram.

In the $P$ - $h$ diagram (Fig. 3 ), the thermodynamic process $1-2$ describes the work of the first-stage compressor during compression of ammonia vapour. Process 1-2 describes the theoretical work of the first-stage compressor during compression of ammonia vapour. Process 2-9 describes the modification of the ammonia vapour thermodynamic parameters in the flash chamber. Process 3-5 describes the work of the second-stage compressor during compression of ammonia vapour. Process 3-5 describes the theoretical work of the second-stage compressor during compression of ammonia vapour. Process 5-7 describes changes in ammonia vapour thermodynamic parameters during condensation. Process 7-8 and 9-10 describe changes in condensed ammonia vapour thermodynamic parameters during throttling. Process 10-1 describes changes in ammonia thermodynamic parameters during evaporation (freezer cooling). 


\section{RESUlts}

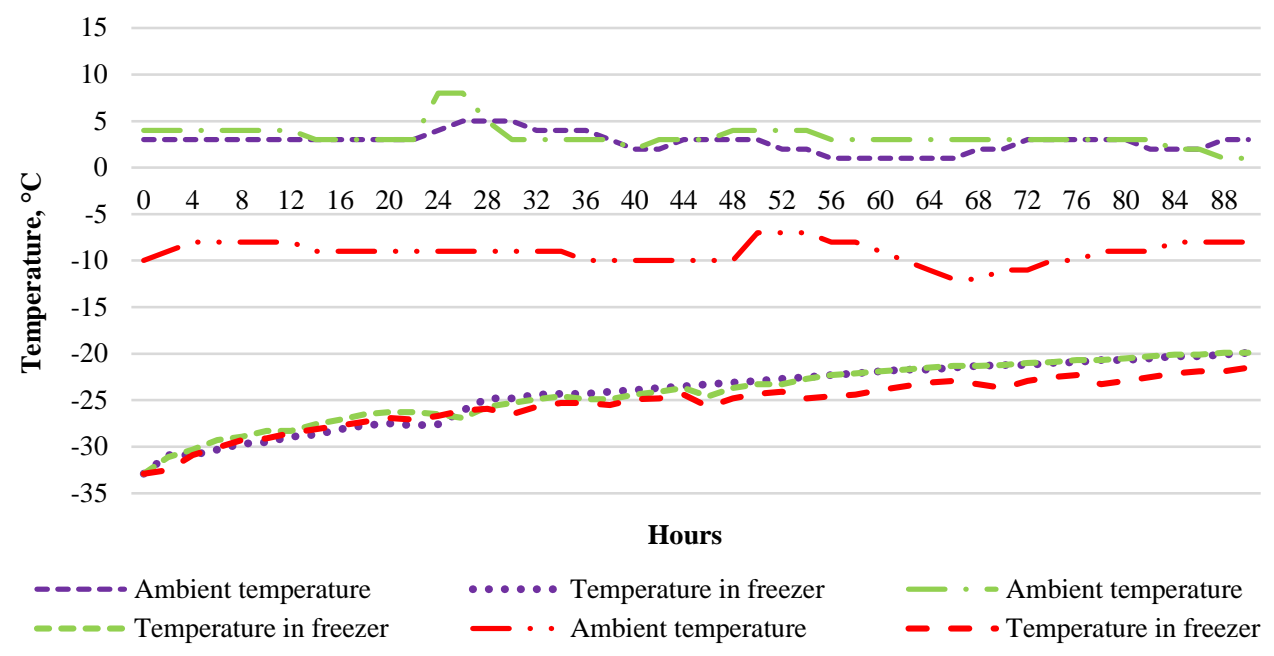

Fig. 4. Freezer warm-up speed.

Fig. 4 shows temperature changes in the freezer after the freezing equipment is switched off. From the information shown, it can be concluded that, over the course of 90-hours, the freezer warms-up from $-32{ }^{\circ} \mathrm{C}$ to $-20^{\circ} \mathrm{C}$ from the moment of disconnection. From the graph it can be concluded that the outdoor temperature influences the freezer warming, as the freezer warming to the negative outdoor temperatures is slower than at positive outdoor temperatures. Thus, it can be concluded that the heat (cold) losses of the freezer are influenced by the temperature of the environment, which, in turn, affects the consumption of electricity for the freezer cooling.

To reduce freezer warming between refrigeration, the last frozen fish batch is left in the freezer. This would increase the cold inertia of the freezer, which would reduce freezer warming. This would reduce the power consumption of the refrigeration equipment needed to reach the required freezer temperature.

After processing the data on the refrigeration system, figures of electricity consumption for freezing and storing fish were established. 


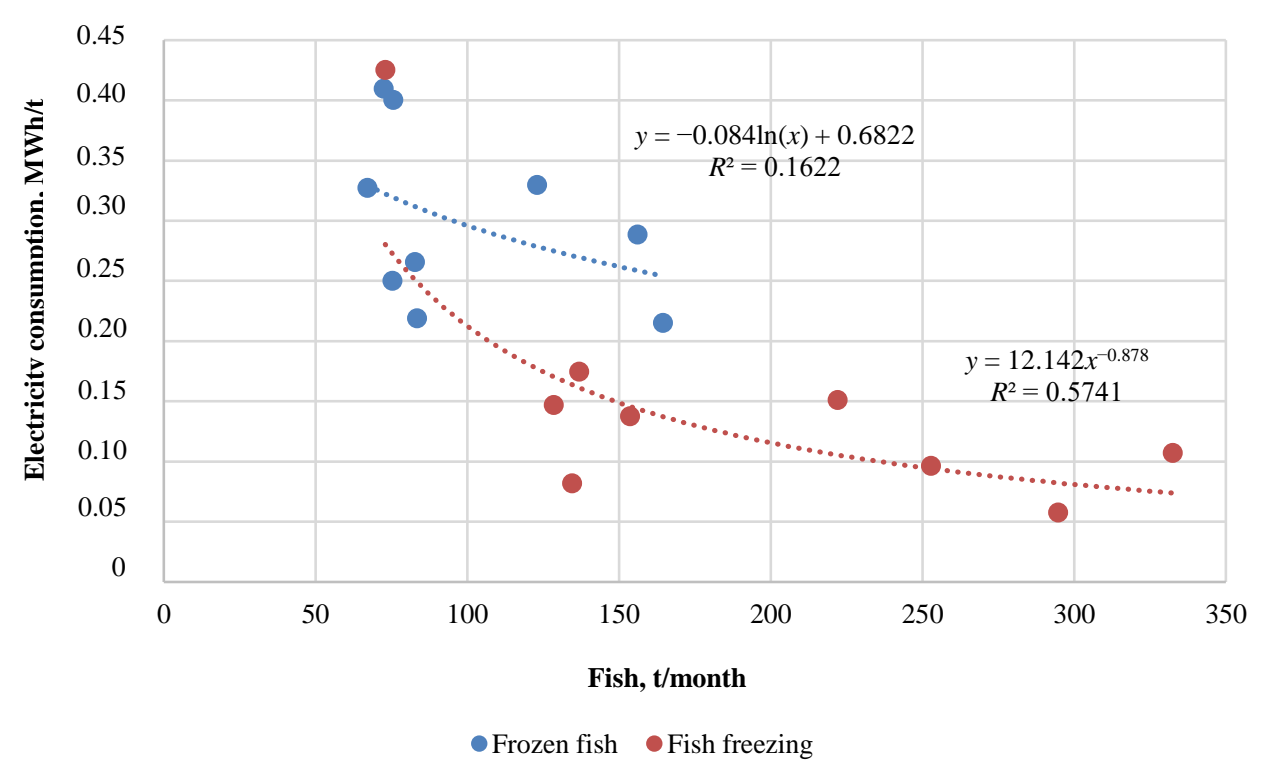

Fig. 5. Fish freezing and frozen fish storage.

From the results of the freezing of fresh fish (Fig. 5) it can be concluded that the specific consumption of electricity decreases with the increase of frozen fish volumes. These changes can be explained by the fact that the more frequent freezing of fish (the greater the amount of fresh fish per month), the less time is needed to cool the freezer and reach the required temperature in the freezer.

The correlation coefficient shows that there is a connection between the amount of fish to be frozen and the consumption of electricity for the freezing process. Thus, the equation indicated in the graph could use for forecasting the consumption of electricity at the specific volumes of freezing fish per month.

From the obtained results (Fig. 5) it can be concluded that the specific consumption of electricity in the storage of frozen fish changes with minimal changes in the volumes of frozen fish. One of the options for such a specific distribution of electricity consumption is the effect of ambient temperature on the loss of heat (cold) from the freezer, as well as on equipment used in the freezing process, such as a condenser. To test this statement, graphs were created to analyse the freezer warm-up speed, depending on the outdoor temperature at times when the freezer is not working. In addition, an analysis was performed to understand whether the ambient parameters, i.e. the temperature of the water used for cooling the condenser and the condenser itself, influenced the electricity consumption of the refrigeration equipment.

The following graphs will analyse the COP of a two-stage and one-stage compressor, when the various parameters related to compressor operation changes. 


\subsection{Coefficient of Performance (COP) of Two-Stage Refrigeration System and Parameters Affecting COP}

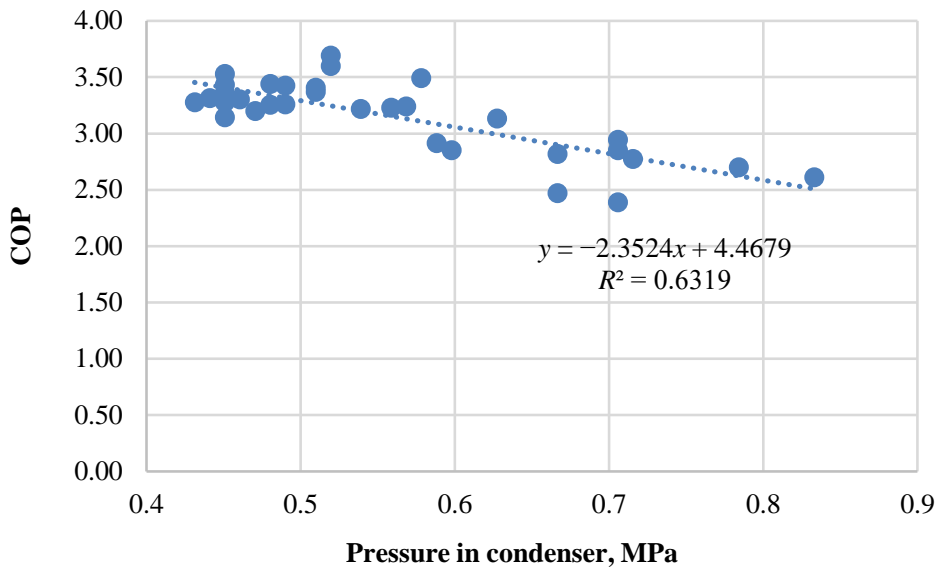

Fig. 6. Two-stage compressor COP depending on condenser pressure.

Considering the two-stage compressor operation data and the thermodynamic cycle, calculations of the compressor efficiency (COP) are made (Fig. 6). The results of the calculations show that the two-stage compressor efficiency coefficient (COP) ranges from 2.4 to 3.7. From the data shown in Figure 6, it can be concluded that the COP is affected by the pressure in the condenser; the higher the pressure in the condenser, the smaller the COP and vice versa.

The correlation coefficient shows that there is a connection between compressor efficiency and condenser pressure. Thus, the equation shown in the graph could be used to predict the efficiency of the compressor at a specific condenser pressure, where " $x$ " denotes the pressure in the condenser but " $y$ " the compressor efficiency or the COP.

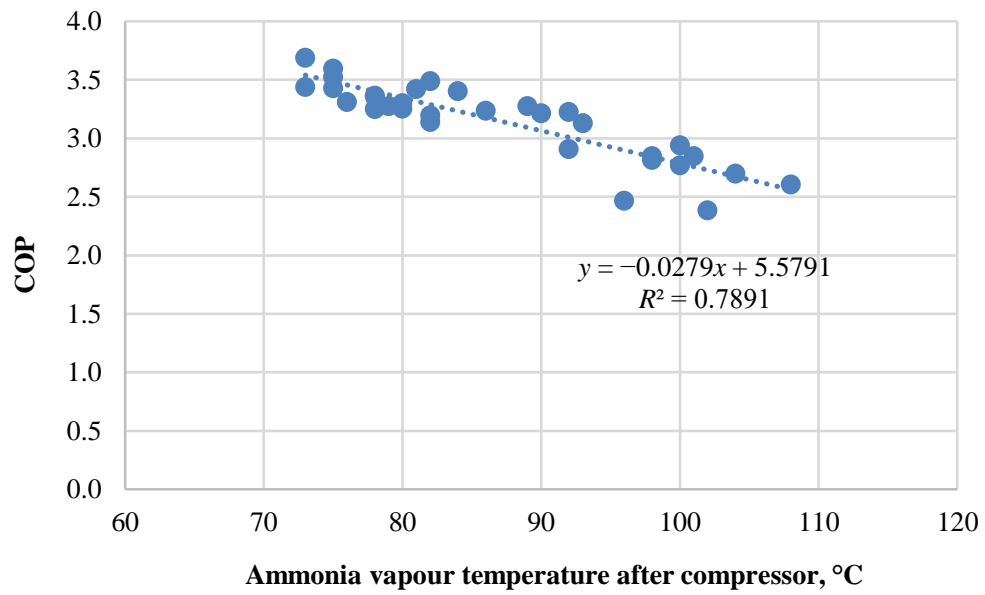

Fig. 7. Two-stage compressor COP depending on ammonia vapour temperature after compressor. 
The graph (Fig. 7) shows the results of ammonia vapour temperature after the compressor effect on the compressor COP. From the results, it can be concluded that the ammonia temperature after the compressor increases, the compressor COP decreases. This correlation is also confirmed by the correlation coefficient $R$. As the COP decreases, electricity consumption increases to produce one unit of cold energy. Thus, the equation shown in the graph can be used to predict the efficiency of the compressor at specific ammonia vapour temperature at the compressor, where " $x$ " stands for ammonia temperature at the compressor, but " $y$ " at compressor efficiency or COP.

\subsection{Coefficient of Performance (COP) of Single-Stage Refrigeration System and Parameters Affecting COP}

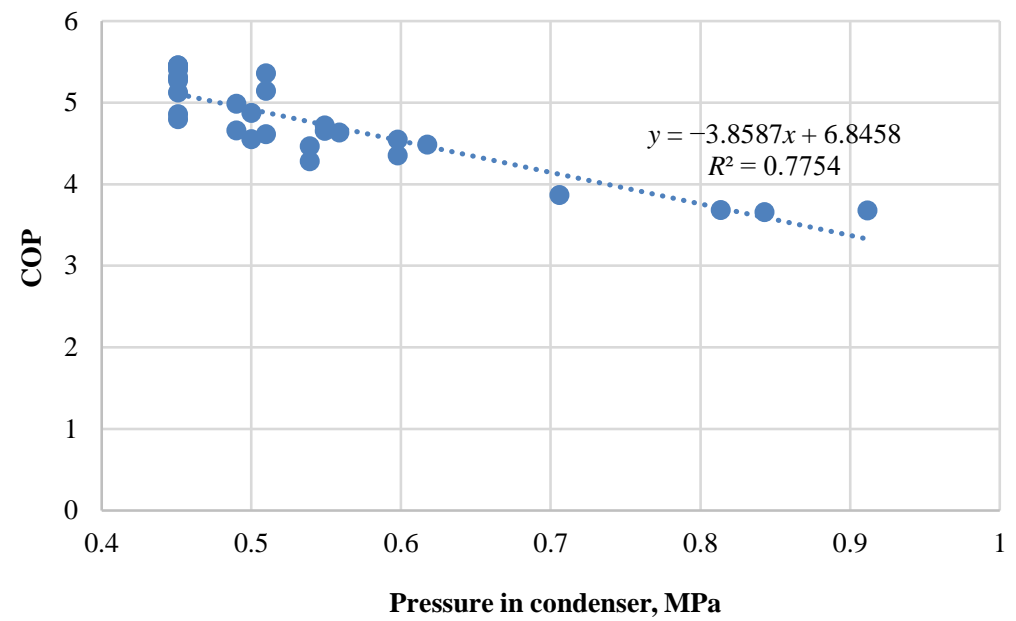

Fig. 8. Single-stage compressor COP depending on condenser pressure.

Based on single-stage compressor performance data and thermodynamic cycle, calculations of compressor efficiency or COP were performed. From the results (Fig. 8) of the calculations it can be concluded that the single-stage compressor efficiency coefficient (COP) ranges from 3.7 to 5.5. From the data shown in Figure 8, it can be concluded that the COP is affected by the pressure in the condenser; the higher the pressure in the compressor, the smaller the COP and vice versa.

The correlation coefficient shows that there is a connection between compressor efficiency and condenser pressure. Thus, the equation shown in the graph can be used to predict compressor efficiency at a specific condenser pressure, where " $x$ " denotes the pressure in the condenser but " $y$ " - compressor efficiency (COP). 


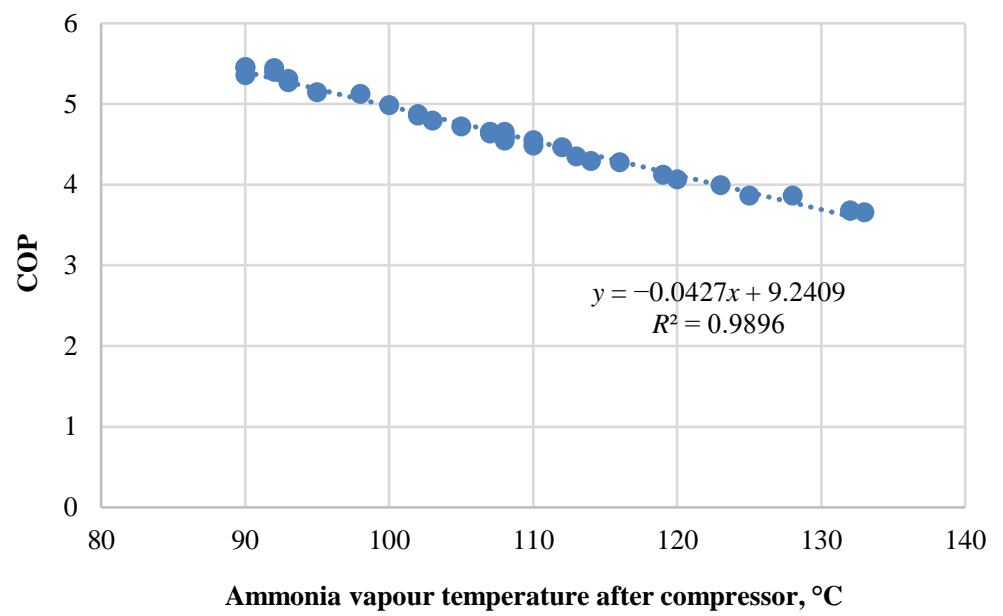

Fig. 9. Single-stage compressor COP depending on ammonia vapour temperature after compressor.

The graph (Fig. 9) shows the results of ammonia vapour temperature after the compressor effect on the compressor COP. From the results, it can be concluded that the ammonia temperature after the compressor increases, the compressor COP decreases. This correlation confirmed by the high value of correlation coefficient $R$. As the COP decreases, electricity consumption increases to produce one unit of cold energy.

\subsection{Condenser Pressure and Ammonia Vapour Temperature after the Compressor Changes Depending on Cooling Water Temperature}

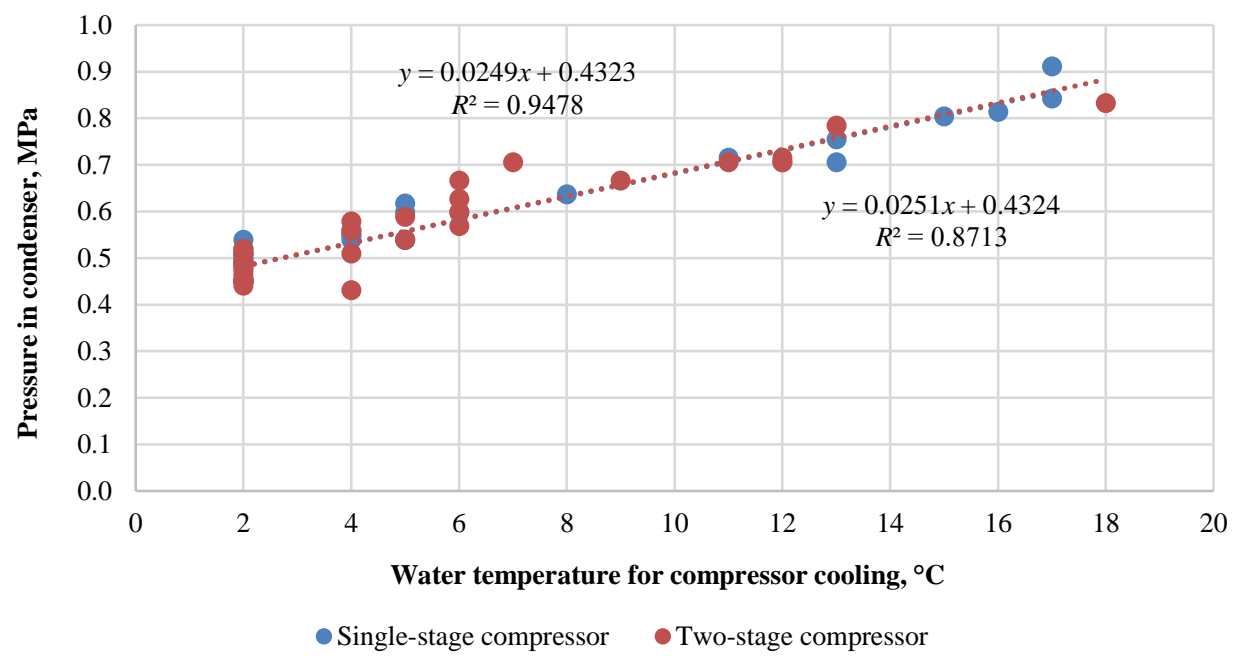

Fig. 10. Single-stage and two-stage compressor condenser pressure depending on cooling water temperature.

The graph (Fig. 10) shows information on the effect of condenser cooling water temperature on single-stage condenser pressure. From the information shown, it can be concluded from the graph that the pressure in the condenser increases as the temperature of the water used for cooling the condenser increases, which also confirmed by the correlation coefficient $R$. Thus, 
the equation shown in the graph is used to predict condenser pressure at the water temperature of the compressor cooling, where " $x$ " denotes the water temperature for condenser cooling, but " $y$ " - the condenser pressure.

The graph (Fig. 10) shows information on the effect of condenser cooling water temperature on two-stage compressor condenser pressure. From the information shown, it can be concluded that the pressure in the condenser increases as the temperature of the water used for cooling the condenser increases, which is also confirmed by the correlation coefficient $R$. Thus, the equation shown in the graph is used to predict condenser pressure at the specific condenser cooling water temperature, where " $x$ " denotes the water temperature for condenser cooling, and " $y$ " - condenser pressure.

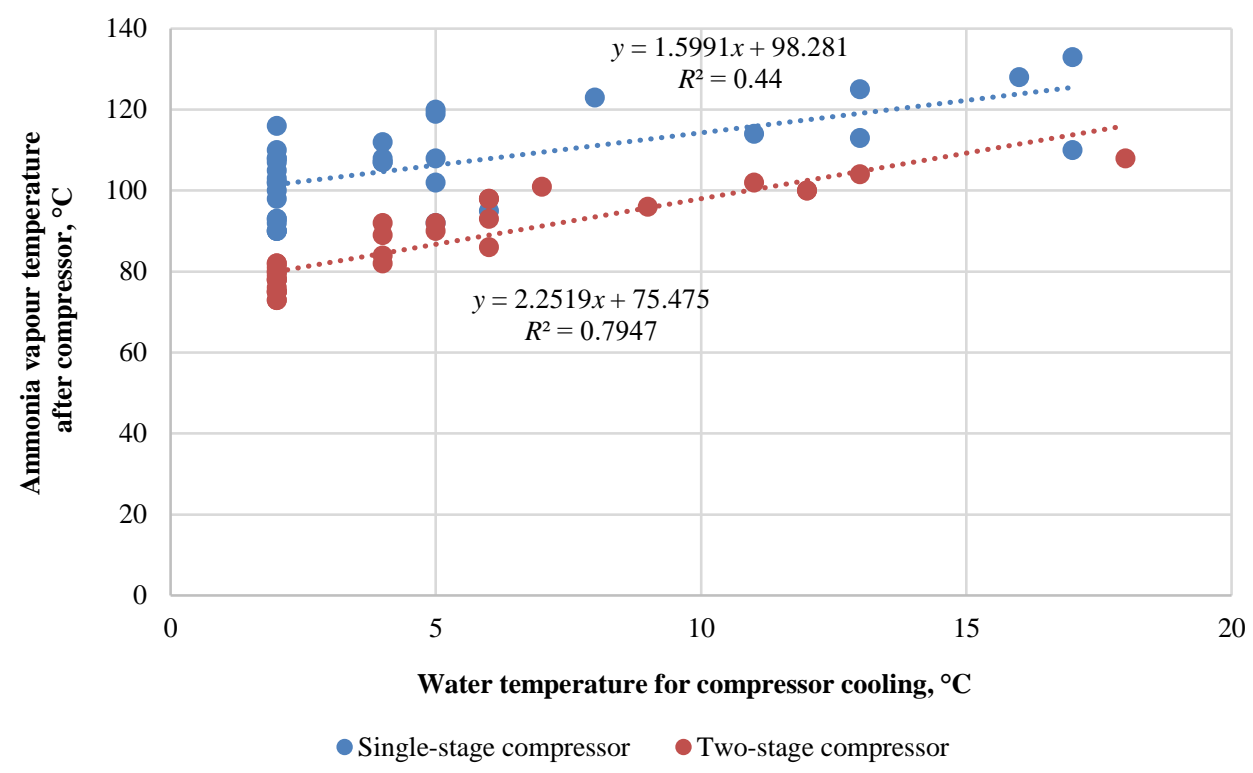

Fig. 11. Single-stage and two-stage compressor ammonia vapour temperature depending on cooling water temperature.

The graph (Fig. 11) shows information on the effect of compressor cooling water temperature on the ammonia vapour temperature after the single-stage compressor. From the graph below, it can be concluded that the temperature of the ammonia after the compressor increases with the temperature of the water used for cooling the compressors, which is also confirmed by the correlation coefficient $R$.

The graph (Fig. 11) shows information on the effect of compressor cooling water temperature on the ammonia vapour temperature after the two-stage compressor. From the graph, it can be concluded that the temperature of the ammonia after the compressor increases with the temperature of the water used for cooling the compressors, as evidenced by the correlation coefficient $R$.

Thus, both equations shown in the graph can be used for the ammonia vapour temperature after the compressor at the specific water temperature of the compressor cooling, where " $x$ " denotes the water temperature for cooling the compressor, and " $y$ " denotes the ammonia vapour temperature after the compressor. 


\section{Conclusions}

It can be concluded from the results that the specific consumption of electricity for freezing of fish is lower than storage of frozen fish. The two-stage compressor COP ranges from 2.4 to 3.7 , but the one-stage compressor COP ranges from 3.7 to 5.5 .

The operation of both compressors affected by the pressure in the condenser and the temperature of the ammonia vapour after the compressor, i.e., with the increase of ammonia vapour temperature and pressure in the condenser, the compressor COP decreases. This increases the required power consumption required to produce one unit of cold energy.

The pressure in the condenser and the ammonia vapour temperature after the compressor affected by the temperature of the water used to cool the condenser and compressors. As the temperature of the water used for cooling increases, the temperature in the condenser and ammonia vapour increases after the compressor, which, in turn, reduces the compressor COP.

One-stage compressor works more efficiently when the COP is 5.45 at a pressure in the condenser of $0.45 \mathrm{MPa}$ and the ammonia vapour temperature after the compressor $90{ }^{\circ} \mathrm{C}$, but ineffective when the COP is 3.65 at the pressure in the condenser $0.84 \mathrm{MPa}$ and the ammonia vapour temperature after the compressor is $133{ }^{\circ} \mathrm{C}$.

\section{REFERENCES}

[1] Tomczak-Wandzel R., Arctander E., Wandzel T. BAT in fish processing industry. Nordic perspective. Copenhagen: Nordisk Ministerrad, 2015. doi:10.6027/TN2015-566

[2] Luyben W. L. Control of compression refrigeration processes with superheat or saturatedboiling. Chemical Engineering \& Processing: Process Intensification 2019:138:97-110. doi:10.1016/j.cep.2019.03.005

[3] Ruangtrakoon N., Aphornratana S. Design of steam ejector in a refrigeration application based onthermodynamic performance analysis. Sustainable Energy Technologies and Assessments 2019:31:369-382. doi:10.1016/j.seta.2018.12.014

[4] Khan N., et al. Energy and Exergy Analysis of Vapour Compression Refrigeration System with R12, R22, R134a. International Journal of Emerging Technology and Advanced Engineering 2015:5(3):1-7.

[5] Jianbo L., et al. Experimental study on absorption/compression hybrid refrigeration cycle. Energy 2019:168:1237-1245. doi:10.1016/j.energy.2018.11.093

[6] Blumberga A., Timma L., Blumberga D. System Dynamic Model for the Accumulation of Renewable Electricity using Power-to-Gas and Power-to-Liquid Concepts. Environmental and Climate Technologies 2015:16(1):54-68. doi:10.1515/rtuect-2015-0012

[7] Leducq D., Pirano M., Alvarez G. Energy savings potential using the thermal inertia of a low temperature storage. Presented at the 24ième Congrès International du Froid ICR Yokohama, Japan, 2015.

[8] de Carvalho S. M. R., et.at. Optimization of a vapor injection refrigeration cycle using hydrocarbon mixed refrigerants. International Journal of Refrigeration 2019:98:109-119. doi:10.1016/j.ijrefrig.2018.10.008

[9] Terehovics E., et al. Analysis of fish refrigeration electricity consumption. Energy Procedia 2018:147:649-653. doi:10.1016/j.egypro.2018.07.084

[10] Latosov E., et al. The Impact of Parallel Energy Consumption on the District Heating Networks. Environmental and Climate Technologies 2019:23(1):1-13. doi:10.2478/rtuect-2019-0001

[11] Murthy A. A., et al. A Review on Expanders and their Performance in Vapour Compression Refrigeration Systems. International Journal of Refrigeration 2019:106:427-446. doi:10.1016/j.ijrefrig.2019.06.019

[12] Lallouche A., et al. Low Temperature Refrigeration as an Alternative Anti-Pest Treatment of Dates. Environmental and Climate Technologies 2017:20(1):24-35. doi:10.1515/rtuect-2017-0008

[13] Dincer I., Kanoglu M. Refrigeration Systems and Applications. John Wiley \& Sons, Incorporated, 2011.

[14] Alda D., Ciarlo D. Refrigeration Systems, Design Technologies and Developments. Nova Science Publishers, 2013. 